\title{
Change of Poly(vinyl alcohol) Crystal Lattice by Iodine Sorption
}

\author{
Yoon-So ChOI, Yushi OIsHI, ${ }^{*}$ and Keizo MiYaSAKa \\ Department of Organic and Polymeric Materials, Tokyo Institute \\ of Technology, Ookayama, Meguro-ku, Tokyo, Japan
}

(Received October 12, 1989)

\begin{abstract}
Poly(vinyl alcohol) films (PVA) were soaked at $20^{\circ} \mathrm{C}$ in aqueous I-KI solutions with different iodine concentrations. Iodine sorption obeyed a Freundlich isotherm over a range of iodine concentration from $5 \times 10^{-3}$ to $6 \times 10^{-1} \mathrm{moll}^{-1}$. Changes in the PVA crystal lattice with iodine sorption showed that iodine molecules intrude into crystalline, as well as amorphous regions, to form a new "substitution type" crystal lattice. In this lattice, one PVA chain of a hydrogen-bonded pair in the original PVA cell is replaced by a polyiodine chain. The iodination increased the drawability of PVA films. It is not certain, however, whether the enhanced drawability is due to the plasticized amorphous phase alone, as is suggested by depression of the glass transition temperature, or also to the iodinated crystals.
\end{abstract}

KEY WORDS Iodine-Poly(vinyl alcohol) Complex / Drawability / Polyiodine / Doubly-Oriented Poly(vinyl alcohol) Film / Wide Angle X-Ray Diffraction / Poly(vinyl alcohol)-Iodine Cell / Intercalation Model / Substitution Model /

Recently, high drawing of PVA has attracted much interest, ${ }^{1-4}$ because of the successful super-high drawing of ultrahigh molecular weight polyethylene (UHMW-PE) prepared through gelation, which resulted in extraordinarily high-modulus and high-strength fibrous materials. ${ }^{5-9}$ According to reports so far, UHMW-PVA forms easily gels with solvents like ethyleneglycol but both as-formed wet and dried gels have much less drawability than that of UHMW-PE gels. The poor drawability of PVA is largely due to the presence of intermolecular hydrogen bonding between adjacent $\mathrm{OH}$ groups in both crystalline and amorphous regions. It may be reasonable to suppose that the poor drawability of PVA is due more to the drawability of the crystal than that of the amorphous phase. Then enhanced drawability of the crystal is necessary for the enhancement of drawability of PVA.

We have been studying the formation of
iodine-PVA complex and the structure of the complex,,$^{10-13}$ while studying the structure of ultra-highly drawn UHMW-PE single crystal mats $^{14,15}$ and biaxial drawing of the material. ${ }^{16}$

Under these circumstances, we are interested in the modification of the PVA crystal by sorption of some agents. At the first step of the approach, we studied how the PVA crystal changes its structure with iodine sorption. In one of the earliest structural studies on iodine sorption by PVA films, Hess et al. ${ }^{17}$ found new diffraction spots on X-ray photographs of PVA fibers which sorbed iodine more than $12 \mathrm{wt} \%$ and concluded that iodine intruded in the crystal phase as well as in the amorphous at comparatively heavy iodine-sorption. According to Tadokoro et al.,$^{18}$ water which has a high affinity to PVA seems to intrude easily into the crystal of PVA. This implies that iodine which has also an affinity to PVA as strong as

\footnotetext{
* Present address: Faculty of Engineering, Kyushu University, Fukuoka 812, Japan.
} 
making a complex together may intrude in the crystal even at much less sorption than that indicated by Hess et al.

In this paper, the change in the PVA crystal lattice induced by iodine sorption is investigated by $\mathrm{X}$-ray diffraction method over a range of iodine content. The use of doubly-oriented PVA films was effective in this study. The effect of iodine sorption on the drawability of PVA is also investigated.

\section{EXPERIMENTAL}

PVA (Wako Pure Chem. Co., DP=2000) was used after further saponification with sodium methoxide in $\mathrm{Me}-\mathrm{OH}$. The IR spectrum of the PVA detected no trace of acetate groups. Films were cast from a $7 \mathrm{wt} \%$ PVA aqueous solution on PMMA plates in air at $20^{\circ} \mathrm{C}$. For the convenience of X-ray diffraction analysis, doubly-oriented PVA films about $100 \mu \mathrm{m}$ thick were prepared by rolling in one-way in a two-roller mill and subsequent annealing under fixed length at $150^{\circ} \mathrm{C}$ for $3 \mathrm{~min}$. In the films, the (101) crystal plane lies on the film plane while the chain axes orient parallel to the roller-drawn direction. The film was drawn three-times in the rolling direction during rolling. The GR grade of iodine and potassium iodide (Wako Pure Chem. Co.) were used as received. Iodine-potassium iodide aqueous solutions with a mol ratio of $1: 2$ were prepared for soaking of PVA films. The iodine concentration in the solution varied from $5 \times 10^{-3}$ to $4 \times 10^{-1} \mathrm{moll}^{-1}$ to change the amount of iodine-sorption by PVA films. PVA films prepared above were soaked in the iodine solutions at room temperature for $24 \mathrm{~h}$ during which the equilibrium amount of sorption was reached. The amount of iodine sorption was determined from the weight difference of a dry film before and after soaking.

All X-ray measurements were carried out at room temperature with $\mathrm{Ni}$-filtered and graphite-monochromated $\mathrm{Cu}-K_{\alpha}$ radiation, by taking photographs and scanning intensity profiles, respectively. X-Ray diffraction intensity was measured in a transmission mode using a Rigaku SG-7 diffractometer. The photographs were taken on a Rigaku flat Laue camera with a sample-to-film distance of $3.5 \mathrm{~cm}$, and the intensity scanning was carried out using a Rigaku scintillation counter.

Stress-strain measurements were made with a Tensilon tensile tester, equipped with an environment chamber, at strain rate $0.5 \mathrm{~min}^{-1}$.

\section{RESULTS AND DISCUSSION}

Figure 1 shows the amount of iodine sorbed $(Q)$ by PVA films as a function of the iodine concentration $(C)$ in the soaking solution. The amount is standardized by a weight of PVA measured before iodination. The iodine sorption increases with increasing iodine concentration. It should be noted that the amount of sorption continues to increase even at high iodine concentration. When the data in Figure 1 were replotted, the $\ln Q$ increased linearly with $\ln C$, indicating that the iodine sorption by PVA obeys a Freundlich isotherm. At $50 \mathrm{wt} \%$ iodine sorption, the distribution coefficient of iodine is about 6 which was the

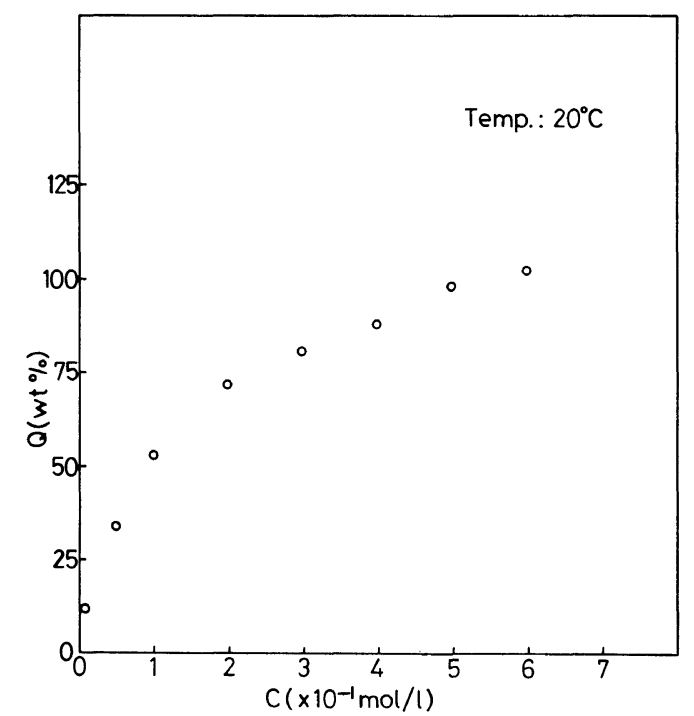

Figure 1. Sorption isotherm of iodine by PVA films at $20^{\circ} \mathrm{C}$. 


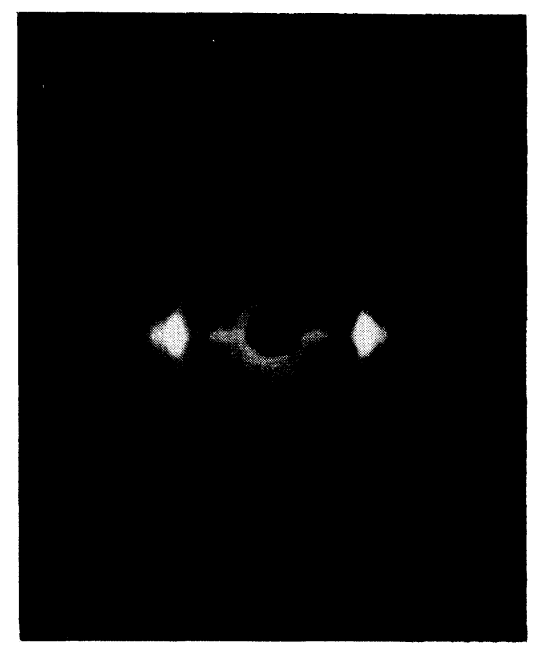

(a)

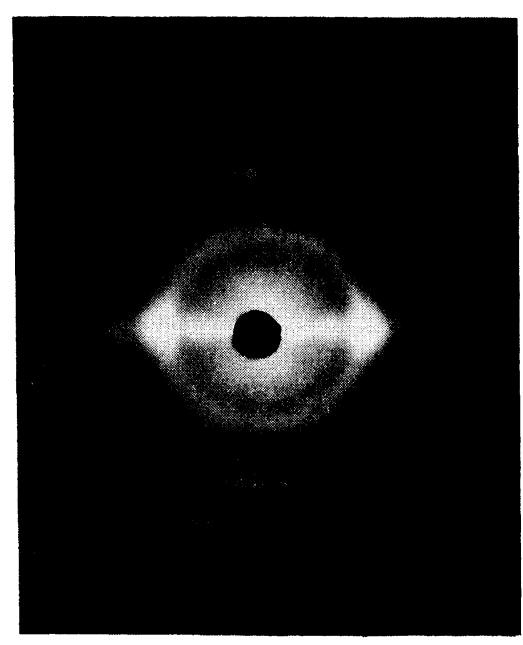

(c)

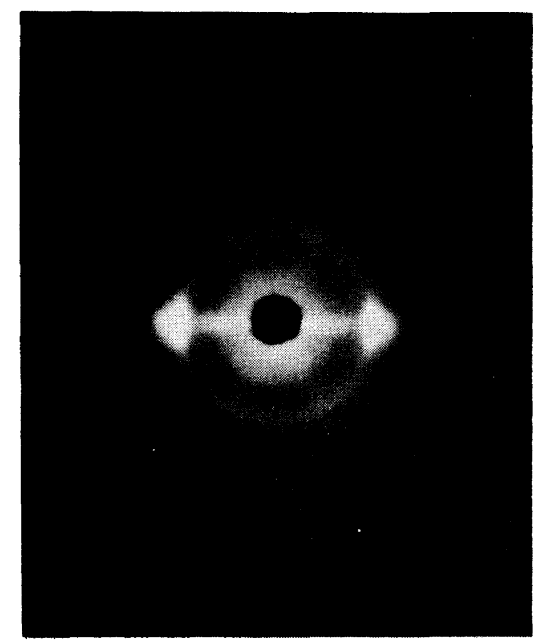

(b)

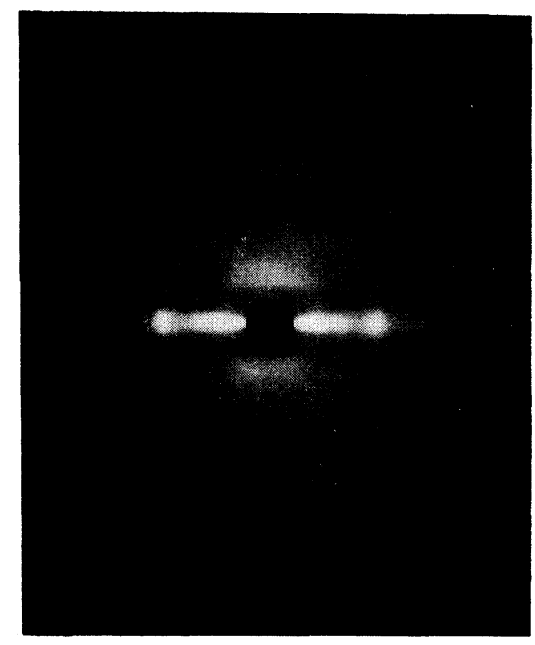

(d)

Figure 2. X-ray diffraction photographs of iodinated PVA films taken with the incident beam normal to the film plane: (a) $0 \mathrm{moll}^{-1}$; (b) $1 \times 10^{-2} \mathrm{moll}^{-1}$; (c) $2 \times 10^{-2} \mathrm{moll}^{-1}$; (d) $4 \times 10^{-1} \mathrm{moll}^{-1}$.

ratio of iodine concentration per water in swollen PVA film to that in the soaking solution, indicating that the concentration in the PVA film is larger than that in the soaking solution.

Figure 2 shows the X-ray diffraction photographs of iodinated PVA films taken with the incident beam normal to the film plane. At comparatively low iodine concentration less than $1.5 \times 10^{-2} \mathrm{moll}^{-1}$, i.e., iodine sorption below about $12 \mathrm{wt} \%$, a new spot appears only on the meridian. At this stage, the diffraction pattern of the PVA crystal remains unchanged except of small change in spacings. This new meridional spot comes from iodine-PVA complex formed in the amorphous region and has been attributed to polyiodines forming a linear lattice of a $3.1 \AA$ periodicity in the complex. ${ }^{19}$ The same meridional diffraction spot as this has been observed in iodinated, 
uniaxially oriented Polyacetylene. ${ }^{20}$ On the other hand, iodine-polyamide system which have amide groups strongly interacting with iodine molecules is different from iodine-PVA system in that iodine chemically modifies the polymer. $^{21,22}$ The action of iodine in polyamide is similar to that of polar solvent. The new equatorial spots begin to appear when the iodine concentration increases over $1.5 \times 10^{-2}$ moll $1^{-1}$ i.e., an iodine sorption over about $12 \mathrm{wt} \%$, as already reported by Hess. ${ }^{17}$ This indicates that iodine intrudes into the crystal to change the lattice. In spite of the remarkable changes in the equatorial diffraction, the characteristic first layer pattern of PVA crystal still remains as it was before iodine sorption, till the concentration over $1 \times 10^{-1} \mathrm{moll}^{-1}$ (50 wt \% iodine sorption). This may be due to the fact that the iodine sorption in the crystal does not take place uniformly through a crystal. In other words, some blocks have been highly iodinated in a crystal while some do not so much. The diffraction pattern becomes completely different from that of the PVA crystal, when the amount of iodine sorption is over $50 \mathrm{wt} \%$. When more than $50 \mathrm{wt} \%$ iodinated specimens were deiodinated by sodium thiosulphate, the diffraction pattern of the PVA crystal recovered again with the same degree and mode of orientation as it originally had before iodination. It is surprizing that deiodination of more than $50 \mathrm{wt} \%$ does not cause any amorphous phase but recovers the original crystalline lattice.

As the first step to study the iodination of the crystal, the lattice dimension was measured for lightly iodinated PVA films. Figure 3 shows the X-ray diffraction photographs of iodinated PVA films taken with the incident beam parallel to the film plane. At these low iodine concentrations of soaking solution, no new equatorial spots appear yet. Figure 4 shows the changes in the $(200),(001)$, and (101) spacings of the PVA crystal with iodine content. It should be marked that the use of doublyoriented specimens made it possible to measure the (101) spacing independent of the (101). From the data in Figure 4, the lattice constants of PVA were calculated as shown in Figure 5. The lattice constants $a, c$, and $\beta$ slightly change with iodine content, indicating that iodine intrudes into PVA crystals even at an early stage of sorption, although the $b$ (chain axis) hardly changes.

Figure 6 shows changes in the equatorial $\mathrm{X}$-ray diffraction intensity curves of PVA films with iodine sorption. In the sample soaked at $2 \times 10^{-2} \mathrm{moll}^{-1}$ (14 wt \% iodine sorption), new equatorial peaks appear at $2 \theta=6.6^{\circ}$ and $2 \theta=$ $13.5^{\circ}$ corresponding to the spacings of 13.38 and $6.58 \AA$. Both of these are not related to any diffractions of the original PVA crystal. Not only these new peaks but also the strongest diffraction peak at $2 \theta=19.4^{\circ}$ assigned to the (101) (101) doublet of PVA crystal shift to higher angle with increasing iodine concentration. These results prove that an "iodine-PVA" cell is formed in heavily iodinated samples, although the cells seem not to form uniformly through a whole crystal, as also suggested by extraordinary broadening of the diffraction profiles. Figure $7(2)$ shows the unit cell we finally reached where the projection onto the $a-c$ plane perpendicular to the chain axis is only shown. This model was constructed on the basis of Bunn's PVA crystal cell in which two chains are arranged so that their $\mathrm{OH}$ groups, supposed to have syndiotactic configuration statistically, may take a "face to face" position to form hydrogen bonds, and the van der Waals radius of iodine atom was taken as $2.15 \AA .^{23}$ This model is first made by substituting a PVA chain with an iodine chain in each original PVA cell, as figured in Figure 7(1) where just as-substituted aspect is preliminarily shown. The cells shown in Figure 7 are noted hereafter as "substitution model." The cell of Figure 7(2) may be reached through the one in Figure 7(1). It is obvious that the packing density of the cell in Figure $7(1)$ is lower than that in Figure 7(2), and therefore the adjustment of packing may take place 


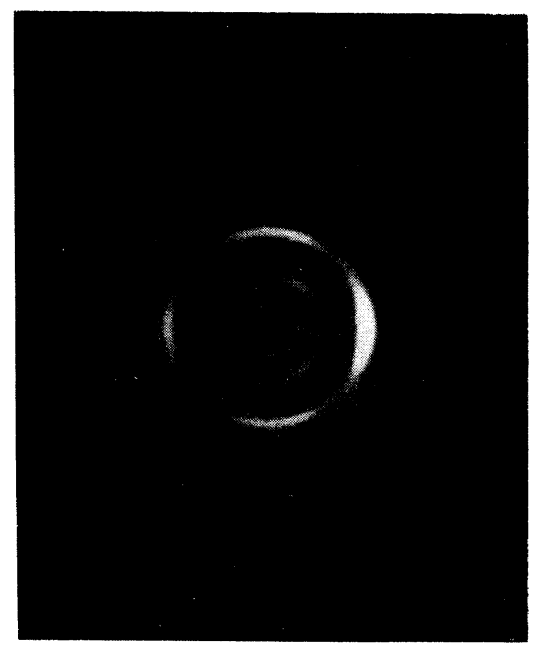

(a)

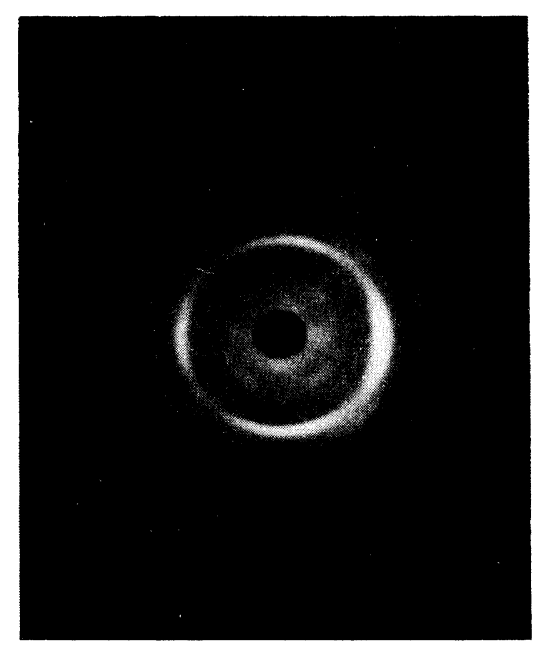

(c)

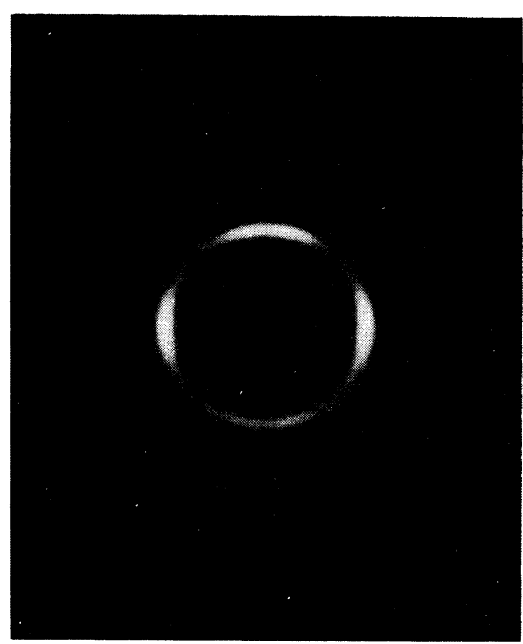

(b)

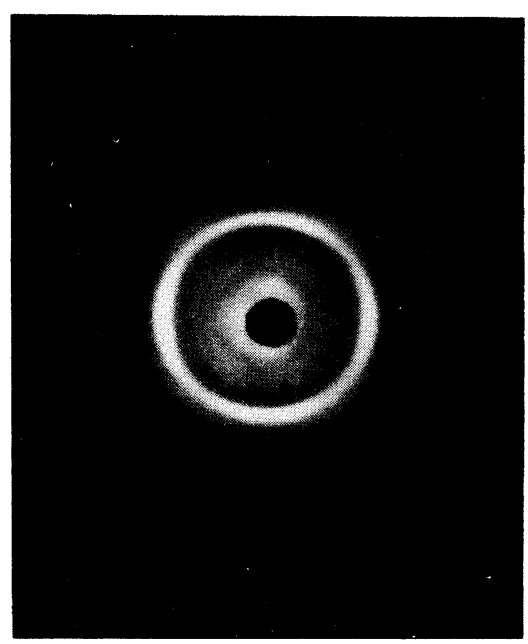

(d)

Figure 3. X-Ray diffraction photographs of iodinated PVA films taken with the incident beam parallel to the film plane: (a) $0 \mathrm{moll}^{-1}$; (b) $5 \times 10^{-3} \mathrm{moll}^{-1}$; (c) $1 \times 10^{-2} \mathrm{moll}^{-1}$; (d) $1.33 \times 10^{-2} \mathrm{moll}^{-1}$.

naturally. The lattice spacings and intensities of the final model in Figure 7(2) are shown in Table I where comparatively good agreements are seen between observed and calculated ones.

In the course of reaching the final model, a "intercalation type model" as shown in Figure 8 was also examined. In this model, a polyiodine is intercalated between two PVA chains facing to each other to form hydrogen bonds. The same sort of intercalation type structure has been found in many complexes. ${ }^{24,25}$ One of the examples is the case of benzamide-iodine complex ${ }^{26}$ in which an $\mathrm{I}_{3}{ }^{-}$ is intercalated between benzamide dimers. The spacing of the "intercalation type" lattice in Figure 8 was as follows: $a=13.45 \AA$ and $c=4.52 \AA$. This lattice well identifies the peaks at $2 \theta=6.5^{\circ}(13.38 \AA)$ and $2 \theta=19.4^{\circ}(4.57 \AA)$ of a $2 \times 10^{-2} \mathrm{moll}^{-1}$ sample in Figure 6 as the (100) and (001) diffractions. However, it fails 


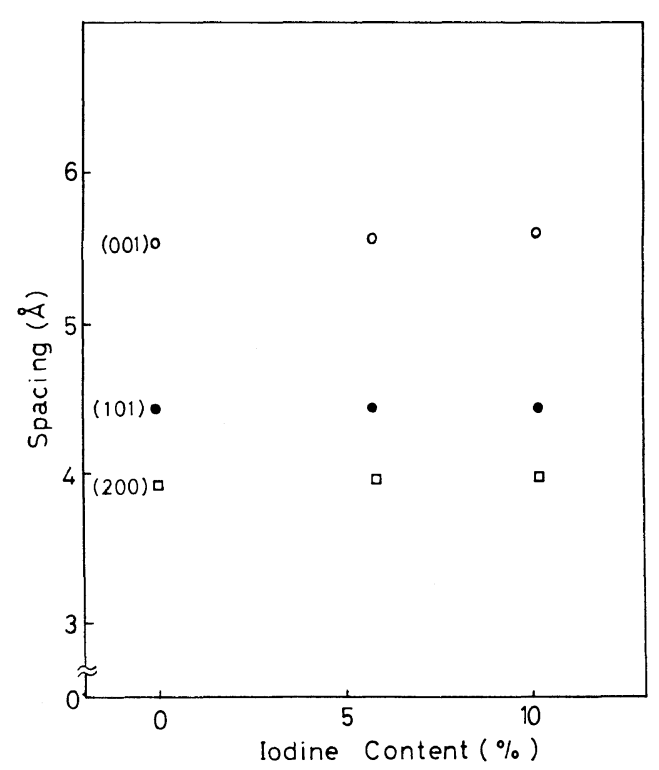

Figure 4. Changes of the spacings of PVA crystal with iodine contents.

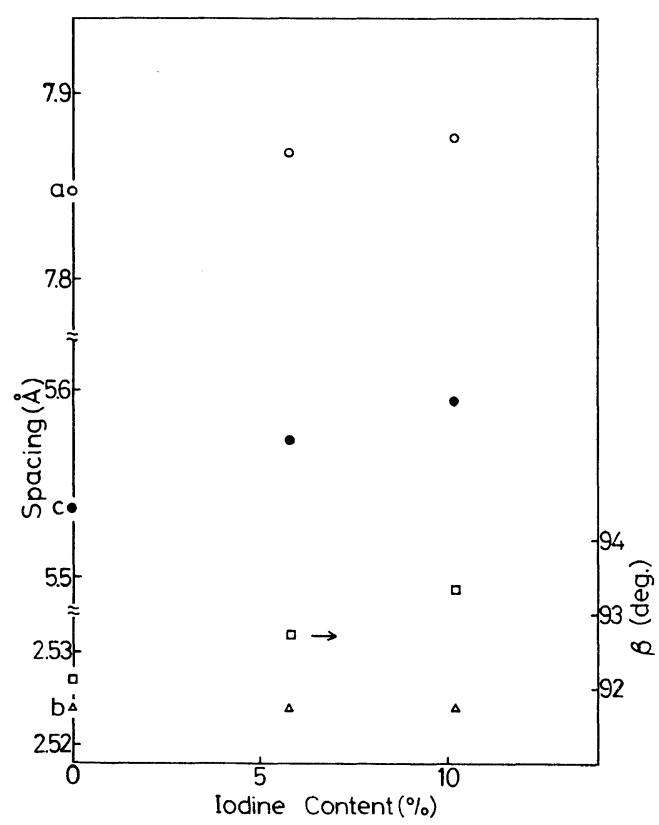

Figure 5. Changes of the lattice constants of PVA crystal with iodine contents.

to identify the peak at $2 \theta=13.5^{\circ}$ of the same sample. These results suggest that the intercalation model in Figure 8 may be formed in such

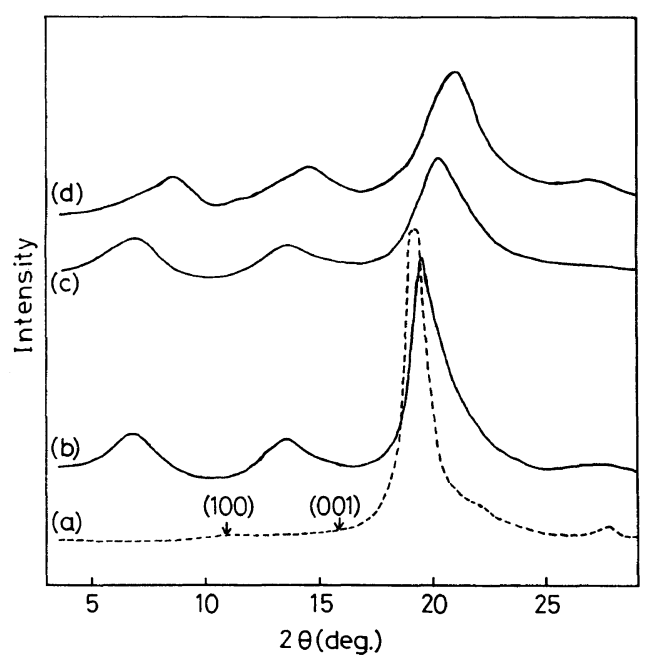

Figure 6. Changes of equatorial X-ray diffraction pattern of iodinated PVA films with iodine sorption: Numbers in a moll $1^{-1}$ unit correspond to the iodine concentration in soaking solution: (a) $0 \mathrm{moll}^{-1}$; (b) $2 \times 10^{-2} \mathrm{moll}^{-1}$; (c) $1 \times 10^{-1} \mathrm{moll}^{-1}$; (d) $4 \times 10^{-1} \mathrm{moll}^{-1}$.

an earlier course of iodine sorption as is the case of $2 \times 10^{-2} \mathrm{moll}^{-1}$ in Figure 6. Some other models than those in Figures 7 and 8 were examined but were found to be less useful than these. It should be noted that even in the substitution model in Figure 7, the iodine chains are embedded in a way that they are intercalated between two PVA chains whose $\mathrm{OH}$ groups take a "face to face" position. It should be repeated to note that the $2 \theta=6.5^{\circ}$ peak of $2 \times 10^{-2} \mathrm{moll}^{-1}$ sample is not identified by the models in Figure 7 but by that in Figure 8, because the spacing is far larger than that expected from the model in Figure 7.

In the substitution model in Figure 7(2) the mol ratio of iodine atom to PVA unit is about $1: 0.8$ and therefore the weight ratio becomes about $1: 1$. It is interesting to remark that in Figure 1 the amount of iodine sorption seems to approach a nearly the same value as suggested weight ratio $100 \%$ for the model in Figure 7(2). So far we studied the change of PVA crystal with iodine sorption, and proposed an iodine-PVA cell, although further 


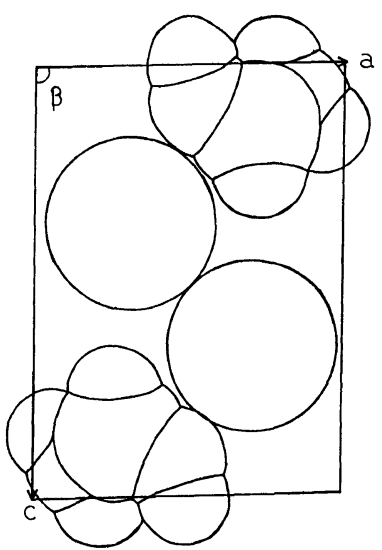

(1)

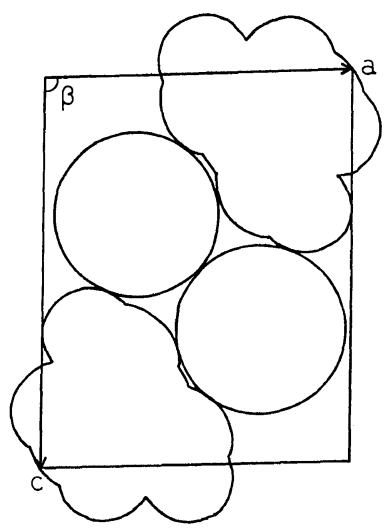

(2)

Figure 7. Substitution models of the unit cell of "iodine PVA" crystal in $a-c$ plane: (1) is the as-substituted model in which the a is the same as that of Bunn's model, while the c is the twice as long as that of Bunn's model. (2) is the finally reached model.

investigations must be required to evidence the reliability of the model. We should remark here that the changes of the crystal lattice spacings were continuous even after the iodine sorption of about $12 \mathrm{wt} \%$ causing a significant change in the equatorial diffraction. This continuous changes in spacing with increasing amount of iodine sorption and the fact that diffraction of PVA crystal still survives after the remarkable changes at $12 \mathrm{wt} \%$ imply again that the iodination of PVA crystal is not caused uniformly through a whole crystal. Even at
Table I. Comparison of observed and calculated spacings and intensities of an iodinated PVA film

\begin{tabular}{|c|c|c|c|c|}
\hline \multirow{2}{*}{ (hkl) } & \multicolumn{2}{|c|}{$d$-Spacing $\AA$} & \multicolumn{2}{|c|}{ Intensity ${ }^{\mathrm{a}}$} \\
\hline & Observed & Calculated & Observed & Calculated \\
\hline 001 & 10.04 & 10.0 & s & s \\
\hline 100 & 7.6 & 7.8 & Shoulder & w \\
\hline $\begin{array}{l}\overline{1} 01 \\
101\end{array}$ & 6.07 & $\left(\begin{array}{l}6.2 \\
6.03\end{array}\right.$ & $\mathbf{s}$ & $\mathbf{s}$ \\
\hline 002 & 5.0 & 5.0 & Shoulder & $\mathrm{w}$ \\
\hline $\begin{array}{l}102 \\
\overline{1} 02\end{array}$ & 4.23 & $\left(\begin{array}{l}4.15 \\
4.26\end{array}\right.$ & vs & vs \\
\hline 003 & 3.29 & 3.33 & w & w \\
\hline
\end{tabular}

${ }^{a}$ vs = very strong; $s=$ strong; $w=$ weak.

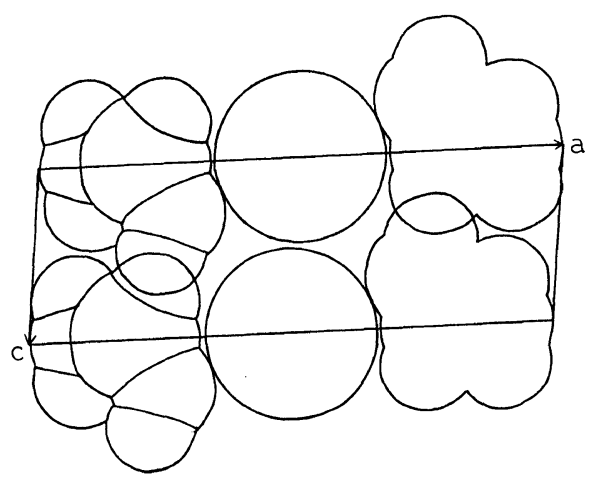

Figure 8. Intercalation model of the unit cell of "iodine-PVA" crystal in $a-c$ plane.

comparatively high sorption stage, some PVA cells must be less iodinated while some have been more iodinated. During the course of the iodination of a crystal, there must be many modes of iodination such as that shown in Figure 8 and others.

In the introductory part of this paper it was pointed out that the deformability of PVA crystal must play an important role governing the drawability of solid PVA materials, and we were interested to enhance the deformability of the crystal by sorption of some agents which effectively decreases the strong interaction due 


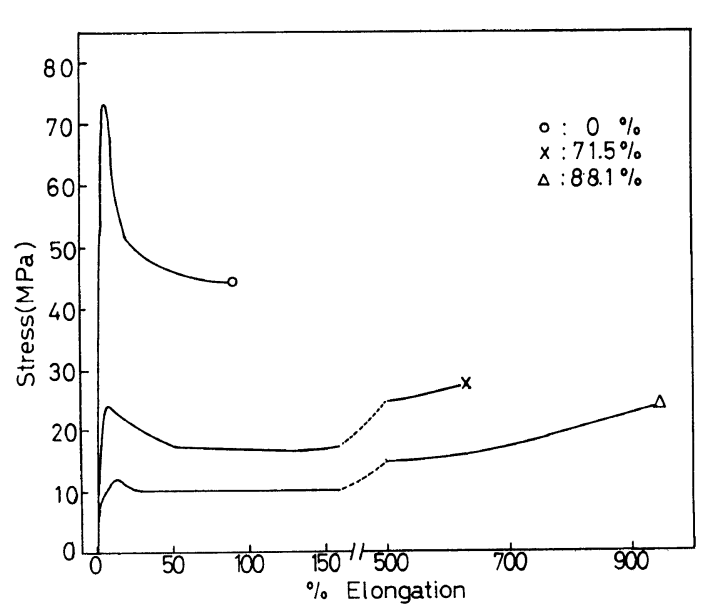

Figure 9. Change of stress-strain curve of PVA film with iodine sorption.

to the hydrogen bonding. Figure 9 shows an example of how the iodine sorption changes the drawability of PVA films. It shows certainly that the drawability of the film increases with iodine sorption. It is, however, uncertain whether this is related to the enhanced deformability of the crystal, since at the same time it was found that the glass transition temperature of the film is much depressed with the iodine sorption. ${ }^{27}$ The studies on enhancing the deformability of PVA is now being performed, and the results will be shown in the following paper.

\section{REFERENCES}

1. Y. D. Kwon, S. Kavesh, and D. C. Prevorsek, US Patent 4440711 (1984).

2. P. Cebe and D. Grubb, J. Mater. Sci., 20,4465 (1985).

3. D. T. Grubb, ACS Topical Workshop, April 5-8
(1986).

4. S. Kiyokawa, Y. Tajima, T. Kanamoto, and H. Sano, Polym. Prepr. Jpn., 37, 2378 (1988).

5. P. Smith, P. J. Lemstra, B. Karb, and A. J. Pennings, Polym. Bull., 1, 733 (1979).

6. P. Smith and P. J. Lemstra, Colloid Polym. Sci., 258, 891 (1980).

7. B. Kalb and A. J. Pennings, J. Mater. Sci., 15, 1584 (1980).

8. P. Smith, P. J. Lemstra, and H. Booij, J. Polym. Sci., Polym. Phys. Ed., 19, 877 (1981).

9. P. J. Lemstra, N. A. J. M. van Aerle, and C. W. M. Bastiaansen, Polym. J., 19, 85 (1987).

10. Y. Kojima, K. Furuhata, and K. Miyasaka, J. Appl. Polym. Sci., 30, 1617 (1985).

11. Y. Oishi and K. Miyasaka, Polym. J., 18, 307 (1986).

12. Y. Oishi and K. Miyasaka, Polym. J., 19, 331 (1987).

13. Y. Oishi, H. Yamamoto, and K. Miyasaka, Polym. J., 19, 1261 (1987).

14. K. Furuhata, T. Yokokawa, and K. Miyasaka, $J$. Polym. Sci., Polym. Phys. Ed., 22, 133 (1984).

15. K. Furuhata, T. Yokokawa, C. Seoul, and K. Miyasaka, J. Polym. Sci. Polym. Phys. Ed., 24, 59 (1986).

16. Y.Sakai and K. Miyasaka, Polymer, 29, 1608 (1988).

17. V. K. Hess, R. Steinmann, H. Kissig, and I. Avisiers, Kolloid-Z.-Z. Polym., 153, 128 (1957).

18. H. Tadokoro, S. Seki, and I. Nitta, Nippon Kagaku Zasshi, 78, 168 (1957).

19. C. D. West, J. Chem. Phys., 15, 689 (1947).

20. T. Danno, K. Miyasaka, and K. Ishikawa, J. Polym. Sci., Polym. Phys. Ed., 21, 1527 (1983).

21. T. C. Tranter and R. C. Collins, J. Tex. Inst. Trans., 52, T88 (1961).

22. H. Arimoto, Koubunsi Kagaku, 19, 101 (1962).

23. L. Pauling, "The Nature of the Chemical Bond," 3rd ed, Cornell University, Ithaca, N.Y., 1960.

24. H. H. Chuah and R. S. Porter, Polymer, 27, 241 (1986).

25. N. S. Murthy, Macromolecules, 20, 309 (1987).

26. J. M. Reddy, Knox, and M. B. Robin, J. Chem. Phys., 40, 1082 (1964).

27. Y. S. Choi, Y. Oishi, and K. Miyasaka, Polym. Prepr. Jpn., 37, 2615 (1988). 